\title{
Platelet indices and outcome after cardiac arrest
}

\author{
Antonella Cotoia ${ }^{1,2}$, Federico Franchi ${ }^{1}$, Chiara De Fazio ${ }^{1}$, Jean-Louis Vincent ${ }^{1}$, Jacques Creteur ${ }^{1}$ \\ and Fabio Silvio Taccone ${ }^{1 *}$
}

\begin{abstract}
Background: Platelet variables, including platelet distribution width (PDW) and mean platelet volume (MPV), have been associated with outcome in critically ill patients. We evaluated these variables in patients after cardiac arrest (CA).

Methods: All adult CA patients admitted to the intensive care unit (ICU) over an 8-year period (2006-2014) and treated with targeted temperature management were included. We retrieved all data concerning CA characteristics as well as platelet count, PDW and MPV on the first 2 days of admission. Unfavorable 3-month neurological outcome was defined as a cerebral performance category score of 3-5.

Results: We included 384 patients (age 62 [52-75] years; 270/384 male): 231 patients (60\%) died within 30-days and 246 patients (64\%) had an unfavorable 3-month neurological outcome. On admission, platelet count, PDW and MPV were $87[126-261]{ }^{*} 10^{3} \mathrm{cells} / \mathrm{mm}^{3}, 17[16.3-17.3] \%$ and 8.3 [7.6-9.2] $\mathrm{\mu m}^{3}$, respectively. Platelet count decreased significantly over the first 2 days, whereas PDW and MPV did not change significantly. There were no significant differences between the values on admission or time-courses of platelet count, PDW or MPV between survivors and non-survivors or between patients with unfavorable and favorable neurological outcome.
\end{abstract}

Conclusions: In our cohort of post-CA patients, PDW and MPV were not associated with outcome.

Keywords: Platelet distribution width, Cardiac arrest, Hypothermia, Platelet indices

\section{Background}

Despite improvements in the management of patients with cardiac arrest (CA), outcomes remain poor, mainly because of associated cardiogenic shock and post-anoxic brain damage [1]. Moreover, the ischemia/reperfusion injury occurring after the return of spontaneous circulation (ROSC) can contribute to a systemic inflammatory response, similar to that observed in septic patients, which may contribute to organ injury [1-4]. The activation of multiple inflammatory pathways results in platelet activation and an imbalance between endogenous coagulation and fibrinolysis pathways $[4,5]$; however, these abnormalities are not easily characterized in clinical practice. In the last few years, there has been increasing interest in platelet variables, such as platelet distribution width (PDW), an indicator of variation in platelet size, and mean platelet volume

\footnotetext{
* Correspondence: ftaccone@ulb.ac.be

${ }^{1}$ Department of Intensive Care, Erasme Hospital, Université libre de Bruxelles, Brussels, Belgium

Full list of author information is available at the end of the article
}

(MPV), for the diagnosis of various conditions associated with altered platelet counts, including sepsis $[6,7]$. These indices, which can be obtained easily from routine blood analysis, have been associated with the occurrence of organ dysfunction during sepsis and an increase in PDW greater than $18 \%$ considered as an expression of platelet activation, both being correlated with mortality [8-10].

PDW and MPV have not been widely studied in survivors of CA [11]. It would be interesting to better characterize the prognostic role of these two biomarkers, as they could be used in the future to identify patients with platelet hyperfunction or increased platelet aggregation after CA, who may require for more aggressive antiplatelet therapy, or those with the highest risk of organ dysfunction or systemic reperfusion injury, who might be treated with specific therapeutic approaches.

We therefore investigated the changes in PDW and MPV over time in CA patients treated with targeted temperature management (TTM) and their relationship with outcome. 


\section{Methods}

The local Ethical Committee (Comité d'Ethique Hospitalo-Facultaire Erasme-ULB) approved the study (Protocol P2017/264), but the need for informed consent was waived because of the retrospective analysis of data. Non-traumatic patients with Glasgow coma scale <9, surviving for at least $24 \mathrm{~h}$ after in-hospital or out-of-hospital CA and admitted to the intensive care unit (ICU) were included in an institutional database (December 2006 to October 2014) and considered eligible for the study. Exclusion criteria were missing data on blood count on admission.

All patients were treated with TTM (target temperature: $32-34{ }^{\circ} \mathrm{C}$ ) for $24 \mathrm{~h}$, according to our standardized protocol that has been described elsewhere [12]. Briefly, cooling is started immediately after ICU admission with a combination of cold fluid bolus (20-30 ml/ $\mathrm{kg}$ of a crystalloid solution in $30 \mathrm{~min}$ ) and a circulating water blanket device (Medi-Therm II, Gaymar, USA). Target temperature is initially measured using a rectal temperature probe or a blood temperature monitoring in case an invasive haemodynamic monitoring (PiCCO, Pulsion, Munich, Germany) is initiated. Sedation is based on the use of midazolam $(0.03-0.1 \mathrm{mg} / \mathrm{kg} / \mathrm{h})$ and analgesia on morphine $(0.1-$ $0.3 \mathrm{mg} / \mathrm{kg} / \mathrm{h}$ ) infusions. Cisatracurium is administered to control shivering in the induction phase (bolus of $0.15 \mathrm{mg} / \mathrm{kg}$ ) and, if needed, as a continuous infusion thereafter (1-3 $\mathrm{mcg} / \mathrm{kg} / \mathrm{min})$. After $24 \mathrm{~h}$ of cooling, rewarming is obtained passively at a rate of $0.3-0.5^{\circ} \mathrm{C} / \mathrm{h}$ and sedation discontinued when body temperature reaches $37^{\circ} \mathrm{C}$. Patients are kept in a $30^{\circ}$ semi-recumbent position; ventilation is set to keep $\mathrm{PaCO}_{2}$ between 35 and $45 \mathrm{mmHg}$ and $\mathrm{SpO}_{2}>94-96 \%$. Blood glucose is kept between 110 and $150 \mathrm{mg} / \mathrm{dL}$ and mean arterial pressure maintained $>65-70 \mathrm{mmHg}$ using fluids, dobutamine and/ or norepinephrine, as appropriate. Intra-aortic balloon counterpulsation (IABP) or extracorporeal membrane oxygenation (ECMO) are used in cases of severe cardiogenic shock.

In case of persisting deep coma associated with bilateral absence of the $\mathrm{N} 20$ response to somatosensory evoked potentials (on day 2-3 after arrest), and/or status myoclonus with malignant EEG (i.e. burst suppression or suppressed background) and/or refractory status epilepticus, decisions to withdraw life-support were made after interdisciplinary discussion and occurred not before $48-72 \mathrm{~h}$ after normothermia $\left(>37^{\circ}\right)$ was restored and sedative agents were stopped.

We collected data on demographics, comorbidities and CA characteristics. The platelet count (normal range: 155-350*10 ${ }^{3}$ cells $/ \mathrm{mm}^{3}$ ), PDW (normal range: 15-18\%) and MPV (normal range: 6.4-10 $\mu^{3}$ ) values were obtained on ICU admission and for two subsequent days from the routine daily blood count measured using the
UniCel DXH 800 Coulter Cellular Analysis System (Beckman Coulter International S.A., Nyon, France). Thrombopenia was defined as a platelet count of $<150 * 10^{3}$ cells/ $\mathrm{mm}^{3}$ while high PDW and MPV in case of values $>18 \%$ and $10 \mu^{3}$, respectively. Blood lactate and C-reactive protein (CRP) levels on admission were also recorded. Treatments with vasoactive/inotropic drugs and continuous renal replacement therapy were noted. Shock was defined as the need for vasopressor agents for more than $6 \mathrm{~h}$. The development of infections during the ICU stay was recorded; survival was recorded at 30-days after admission in ICU. Neurological evaluation was assessed using the cerebral performance category score (CPC) during follow-up visits or by telephone interview 3 months after CA [13]. Unfavorable neurological outcome was considered as a CPC 3-5.

\section{Statistical analysis}

Data were analyzed using SPSS 24.0 for Windows (SPSS Inc., Chicago, IL). We used the Shapiro-Wilk test and stratified distribution plots to verify the normality of distribution of continuous variables. Continuous variables are presented as median [25-75 percentile] and number (\%) as appropriate. Differences between groups (survivors vs. no survivors, and unfavorable vs. favourable outcome) were assessed using Student's T test, Mann-Whitney test, $\chi^{2}$ test, or Fisher's exact test, as appropriate. Time-courses of platelet parameters were analyzed using a two-way ANOVA for repeated measurement with Bonferroni post-hoc correction. A two-tailed test was performed and a $p$ value $<0.05$ was considered to be significant.

\section{Results}

From a total of 445 eligible CA patients admitted over the study period, 43 died within a few hours after hospital admission without blood sampling and 18 were excluded for missing PDW/MPV data, leaving 384 patients for the final analysis (mean age: 62 [52-75]; male gender, $n=270$ [70\%] - Table 1). The total duration of ICU stay was 4 [2-8] days; 231 patients died within day 30 (60\%) and $246(64 \%)$ patients had an unfavorable outcome.

On admission, the platelet count was 193 [131-266] * $10^{3}$ cells $/ \mathrm{mm}^{3}$, PDW 17.0 [16.3-17.3]\% and MPV 8.3 [7.6-9.2] $\mu^{3}$ (Table 1). Platelet counts decreased significantly over the next 2 days to 160 [97-215] on day 1 and 147 [87-202] $* 10^{3}$ cells $/ \mathrm{mm}^{3}$ on day $\left.2, p<0.001\right)$, whereas PDW and MPV remained stable. Thrombopenia was observed in 108 (28\%) patients on admission and in $146(38 \%)$ and 203 (53\%) on day 1 and 2, respectively. High PDW and MPV were observed in 78 (20\%) and 62 (16\%) patients on admission, in 80 (21\%) and 64 (17\%) patients on day 1 and in $82(21 \%)$ and 67 (17\%) patients on day 2 , respectively. 
Table 1 Characteristics of study population according to favourable (FO) and unfavourable (UO) neurological outcome

\begin{tabular}{|c|c|c|c|c|c|c|c|}
\hline & All $(n=384)$ & Survivors $(n=153)$ & Non-survivors $(n=231)$ & $P$ Value & $\mathrm{FO}(n=138)$ & UO $(n=246)$ & $P$ Value \\
\hline Age, years & $62[52-75]$ & $58[49-70]$ & $66[54-78]$ & $<0.001$ & $58[50-69]$ & $66[53-77]$ & $<0.001$ \\
\hline Weight, kg & 77 [67-85] & 78 [70-87] & $75[65-85]$ & 0.360 & 78 [70-88] & 75 [65-85] & 0.076 \\
\hline Male, n (\%) & $270(70)$ & $114(75)$ & $156(67)$ & 0.110 & $103(75)$ & $167(68)$ & 0.165 \\
\hline \multicolumn{8}{|l|}{ Comorbidities } \\
\hline Chronic hypertension, n (\%) & $175(46)$ & $71(46)$ & $104(45)$ & 0.790 & $63(46)$ & $112(45)$ & 0.981 \\
\hline Diabetes, n (\%) & $95(25)$ & $33(22)$ & $62(26)$ & 0.241 & $28(20)$ & $67(27)$ & 0.130 \\
\hline Chronic heart failure, n (\%) & $81(21)$ & $30(20)$ & $51(22)$ & 0.561 & $29(21)$ & $52(21)$ & 0.977 \\
\hline Coronary artery disease, $\mathrm{n}(\%)$ & $168(44)$ & $60(39)$ & $108(47)$ & 0.145 & $56(40)$ & $112(45)$ & 0.348 \\
\hline Neurological disease, n (\%) & $64(16)$ & $17(11)$ & $47(20)$ & 0.028 & $14(10)$ & $50(20)$ & 0.011 \\
\hline Liver cirrhosis, n (\%) & $21(6)$ & $4(3)$ & $17(7)$ & 0.045 & $4(3)$ & $17(7)$ & 0.097 \\
\hline COPD/asthma, n (\%) & $66(17)$ & $23(15)$ & $43(18)$ & 0.362 & $20(14)$ & $46(19)$ & 0.294 \\
\hline \multicolumn{8}{|l|}{ Presentation rhythm, n (\%) } \\
\hline VF-VT, n (\%) & $151(39)$ & $89(55)$ & $62(27)$ & $<0.001$ & $83(60)$ & $68(27)$ & $<0.001$ \\
\hline Unknown, n (\%) & $23(6)$ & $8(5)$ & $15(6)$ & 0.941 & $6(4)$ & $17(7)$ & 0.875 \\
\hline Out of hospital CA, n (\%) & $215(56)$ & $84(55)$ & $131(57)$ & 0.675 & $76(55)$ & $139(56)$ & 0.739 \\
\hline Time to ROSC, min & $15[7-25]$ & $12[5-20]$ & 18 [10-25] & 0.002 & $12[5-20]$ & 17 [10-25] & 0.005 \\
\hline Epinephrine, mg & $3[2-6]$ & $2[1-4]$ & $4[2-7]$ & $<0.001$ & $2[1-4]$ & $4[2-7]$ & $<0.001$ \\
\hline Witnessed CA, n (\%) & $323(84)$ & $138(90)$ & $185(80)$ & 0.006 & $124(90)$ & $199(81)$ & 0.021 \\
\hline Bystander CPR, n (\%) & $255(66)$ & $138(90)$ & $117(50)$ & 0.001 & $107(77)$ & $148(60)$ & 0.001 \\
\hline Cardiac origin of arrest, n (\%) & $230(60)$ & $105(69)$ & $125(54)$ & 0.004 & $97(70)$ & $133(54)$ & 0.002 \\
\hline \multicolumn{8}{|l|}{ During ICU stay } \\
\hline AKI, n (\%) & $231(60)$ & $77(50)$ & $154(67)$ & 0.001 & $69(50)$ & $162(66)$ & 0.002 \\
\hline Vasopressor use, n (\%) & $278(72)$ & $97(63)$ & $181(78)$ & 0.001 & $88(64)$ & $190(77)$ & 0.005 \\
\hline Dobutamine use, n (\%) & $202(53)$ & $77(50)$ & $125(54)$ & 0.252 & $69(50)$ & $133(54)$ & 0.321 \\
\hline Hypothermia, n (\%) & $339(88)$ & $131(85)$ & $208(90)$ & $<0.001$ & $119(86)$ & $220(89)$ & 0.435 \\
\hline Sepsis, n (\%) & $118(31)$ & $45(29)$ & $73(32)$ & 0.649 & $40(29)$ & $78(31)$ & 0.579 \\
\hline IABP, n (\%) & $28(7)$ & $8(5)$ & $20(8)$ & 0.206 & $7(5)$ & $21(8)$ & 0.210 \\
\hline ECMO, n (\%) & $53(14)$ & $20(13)$ & $33(14)$ & 0.736 & $19(14)$ & $34(14)$ & 0.988 \\
\hline CRRT, n (\%) & $60(16)$ & $25(16)$ & $35(15)$ & 0.754 & $22(16)$ & $38(15)$ & 0.898 \\
\hline Shock, n (\%) & $207(54)$ & $66(43)$ & $141(61)$ & 0.001 & $61(44)$ & $146(59)$ & 0.004 \\
\hline Steroid therapy, n (\%) & $74(19)$ & $24(16)$ & $50(22)$ & 0.147 & $23(17)$ & $51(21)$ & 0.333 \\
\hline RBC transfusion, n (\%) & $99(26)$ & $42(28)$ & $57(24)$ & 0.543 & $37(27)$ & $62(25)$ & 0.730 \\
\hline \multicolumn{8}{|l|}{ Blood sample on admission } \\
\hline Creatinine, mg/dL & $1.2[0.9-1.6]$ & $1.1[0.9-1.6]$ & $1.3[0.9-1.7]$ & 0.095 & $1.1[0.9-1.6]$ & $1.2[0.9-1.7]$ & 0.082 \\
\hline Lactate, mg/dL & $4.4[2.8-7.9]$ & $3.9[2.5-5.6]$ & $4.9[3.1-8.7]$ & $<0.001$ & $3.9[2.5-5.7]$ & $4.6[6.0-8.5]$ & 0.003 \\
\hline $\mathrm{CRP}, \mathrm{mg} / \mathrm{L}$ & $11.0[3.6-53.2]$ & $9.0[2.9-49.3]$ & $12.5[4.0-59.0]$ & 0.039 & 7 [2.3-33.1] & $15.1[4.3-64.5]$ & 0.001 \\
\hline $\mathrm{PLT},{ }^{*} 10^{3} \mathrm{cell} / \mathrm{s} / \mathrm{mm}^{3}$ & 193 [131-266] & 196 [133-269] & 193 [133-261] & 0.654 & 197 [134-264] & 194 [130-268] & 0.499 \\
\hline$M P V, \mu m^{3}$ & $8.3[7.6-9.2]$ & $8.4[7.7-9.2]$ & $8.4[7.6-9.3]$ & 0.770 & $8.3[7.7-9.2]$ & $8.4[7.6-9.3]$ & 0.864 \\
\hline$P C T, \%$ & $0.2[0.1-0.2]$ & $0.2[0.1-0.2]$ & $0.2[0.1-0.2]$ & 0.675 & $0.2[0-1-0.2]$ & $0.2[0.1-0.2]$ & 0.774 \\
\hline PDW, \% & $17.0[16.3-17.3]$ & $17.0[16.2-17.3]$ & $17.0[16.4-17.4]$ & 0.422 & 16.8 [16.2-17.3] & $16.9[16.4-17.4]$ & 0.628 \\
\hline ICU length of stay, days & $4[2-8]$ & $7[4-13]$ & $4[2-7]$ & $<0.001$ & $6[4-12]$ & $4[2-8]$ & $<0.001$ \\
\hline
\end{tabular}

CA cardiac arrest, CPR cardiopulmonary resuscitation, ROSC return of spontaneous circulation, VFNT ventricular fibrillation/ventricular tachycardia, AKI acute kidney injury, ICU intensive care unit, IABP intra-aortic balloon pump counterpulsation, ECMO extracorporeal membrane oxygenation, CRRT continuous renal replacement therapy, COPD chronic obstructive pulmonary disease, $R B C$ Red Blood Cells, MV mechanical ventilation, CRP C-reactive Protein, PLT Platelet count, MPV Mean platelet volume, PCT Plateletcrit, PDW Platelet Distribution Width 
Compared to survivors, non-survivors were older, had less frequently had a witnessed arrest, bystander CPR, a cardiac origin of the arrest and an initial shockable rhythm, and had longer resuscitation times and higher epinephrine doses (Table 1). They also had higher admission lactate and CRP concentrations, more frequently received vasopressor therapy, and had a shorter ICU length of stay.

There were no significant differences between survivors and non-survivors in admission platelet counts (196 [133-269] vs. $193[133-261] * 10^{3}$ cells $\left./ \mathrm{mm}^{3}, p=0.65\right)$, PDW (17.0 [16.2-17.3] vs. $17.0[16.4-17.4] \%, p=0.42)$ and MPV (8.4 [7.7-9.2] vs. 8.4 [7.6-9.3] $\left.\mu \mathrm{m}^{3}, p=0.77\right)$. The platelet count decreased significantly during the first 2 days of admission in survivors and non-survivors, whereas PDW and MPV remained stable in the two groups (Figs. 1a, 2a-b). Similar results were found when comparing patients with favourable and unfavourable outcomes (Table 1, Fig. 1b), between patients with in-hospital and out-of-hospital CA and between male and female gender (data not shown). Also, the number of patients with thrombopenia, high PDW or high MPV was similar between survivors and non-survivors or those with favourable and unfavourable neurological outcome on admission, as on day 1 and 2 .

\section{Discussion}

The platelet count decreased during the first $48 \mathrm{~h}$ after CA, but the PDW and MPV did not change; moreover, changes in platelet count, PDW and MPV were not associated with patient outcome.

Post-CA syndrome is associated with a decrease in the number of platelets more than an alteration in their function [2]; the etiology of the reduced platelet count may be related to a systemic inflammatory response, triggered by the ischemia/reperfusion injury occurring after the return of spontaneous circulation, and promoting the systemic activation of platelets [14]. The decrease in platelet count was unlikely to be associated with the
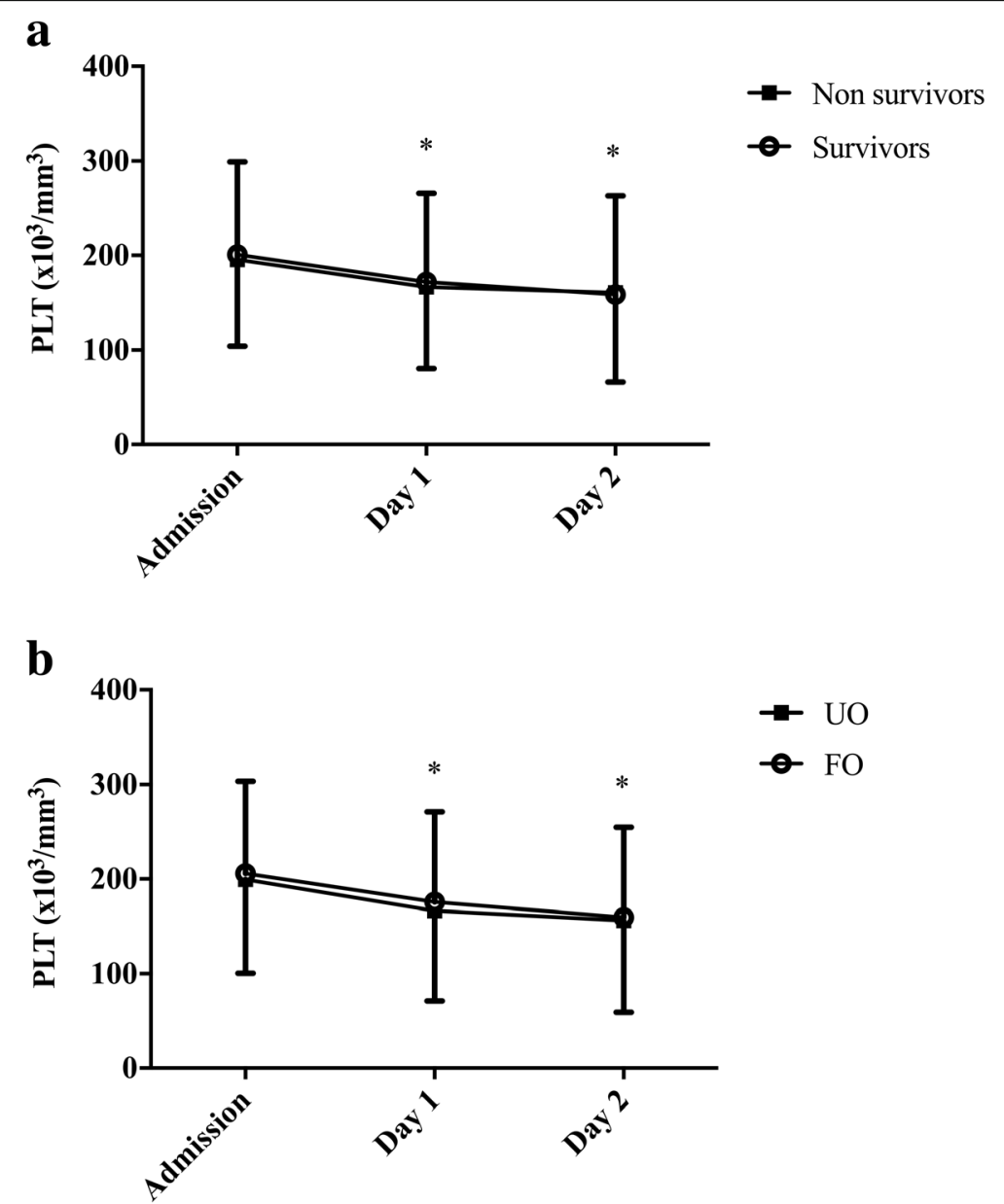

Fig. 1 a Time-course of platelet count (PLT) in survivors and non-survivors and $\mathbf{b}$ ) time-course of platelet count (PLT) in patients with favorable (FO) and unfavorable (UO) neurological outcome. Data are presented as mean \pm SD. * $=$ Significant difference at day 1 and 2 compared to baseline in both survivors and non-survivors, and in patients with favourable and unfavourable neurological outcome $(p<0.001)$ 


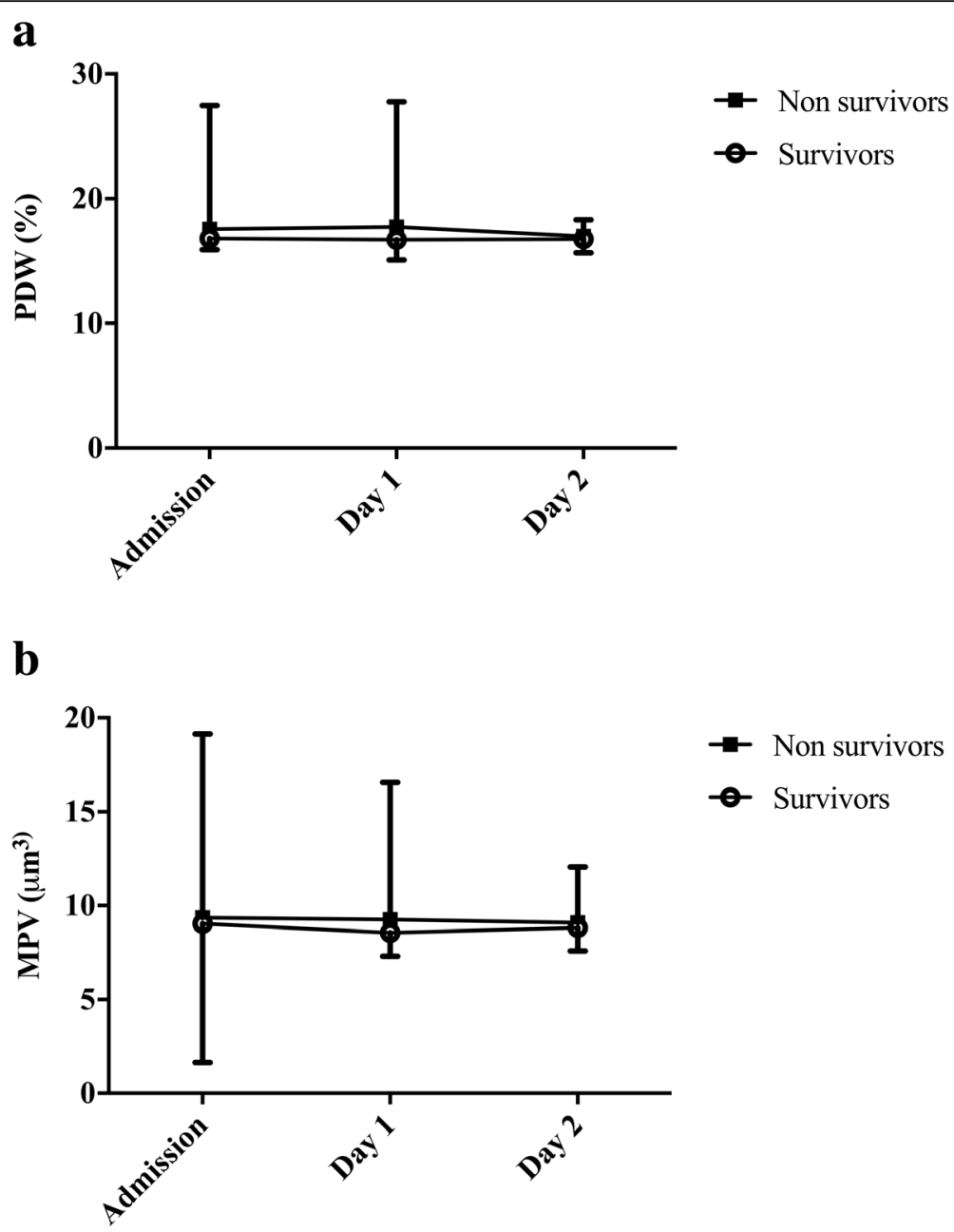

Fig. 2 a Platelet distribution width (PDW) values and b) Mean platelet volume (MPV) in survivors and non-survivor. Data are presented as mean \pm SD. Repeated measures analysis showed no difference in PDW and MPV values over time between survivors and non-survivors $(p>0.05)$

TTM, because platelet count, activation and/or aggregation are not influenced by a moderate decrease in body temperature to $32-34{ }^{\circ} \mathrm{C}$ [15]. The prognostic role of platelet count and/or thrombopenia has been rarely described in CA patients; in one study, Nobile et al. showed no differences in the occurrence of haematological failure (i.e. platelet count $<50 * 10^{3} \mathrm{cells} / \mathrm{mm}^{3}$ ) among survivors and non-survivors after CA $(n=469)$ [16], but patients with OHCA had a greater incidence of hematologic failure than those with IHCA, both on ICU admission ( $7 \%$ vs. $2 \% ; p=0.04)$ and during the ICU stay ( $14 \%$ vs. $7 \%, p=0.009)$.

Herein, changes in PDW or MPV during could represent an important but yet unreported component of the post-CA syndrome [14]. Several studies have reported the prognostic value of PDW or MPV in critically ill patients, focusing on the fact that an increase in these variables reflects the variation in platelet size caused by platelet activation [9, 17-19]. In our study, the lack of association between these variables and outcomes may suggest that the platelet activation occurring as a result of ischemia/reperfusion injury following CA differs from that induced by sepsis or other forms of critical illness. While no study on PDW in CA patients has been published so far, Chung et al. investigated whether MPV was associated with 30-day neurologic outcome and mortality after CA. In 184 patients with OHCA, increased 30-day mortality and poor neurological outcome rate were associated with MPV on admission [20]. Further studies are needed to investigate this phenomenon by including additional tests of platelet activation and aggregation and/or thromboelastometric measurements [21, 22]. Indeed, activated platelets are enlarged, and contain vasoactive and prothrombic factors that aggravate systemic inflammation and endothelial dysfunction. Nevertheless, it is possible that PDW and MPV are not sensitive enough to detect these changes in platelet 
function. In one study, CA secondary to coronary occlusion had the highest degree of platelet hyperfunction, which was tested under high shear rates with the collagen adenosine diphosphate closure time, when compared to other causes of arrest [5]. This condition of platelet hyperfuncion or increased aggregability indicated a pro-coagulopathic state in the post-cardiac arrest phase, which may contribute to the formation of microthrombi (i.e. microvascular dysfunction), but also to early stent thrombosis (i.e. post-arrest acute myocardial infarction) [23]. Thus, future studies should better characterize platelet activity in order to identify patients with enhanced clot formation and who might potentially benefit from a more rapid and aggressive antiplatelet therapy.

Our study has several limitations. First, due to the retrospective design of the study, we do not have all the variables potentially influencing these platelet indices, such as the use of antiaggregants (before arrest or after hospital admission), and the presence of hematological or autoimmune diseases or a previous infectious process, in particular for in-hospital CA. Moreover, some other confounders (i.e. gender, chronic inflammatory diseases, recent trauma or surgery) may also have influenced our findings. Second, we did not specifically collect data on coagulation parameters (such as activated partial thromboplastin time or D-dimers), although these may have been altered by specific therapies (e.g., unfractioned heparin or thrombolysis) administered in CA patients. Also, the combination of intravenous and/or oral platelet drug inhibitors, which was not available for this cohort, may also have affected our results; future studies on the use of different drugs after percutaneous coronary interventions should prospectively evaluate whether PDW and MPV are affected by such interventions and whether this phenomenon would be drug- and/or dose-related. Third, we did not look at specific organ dysfunctions and their relationship with platelet count, PDW or MPV. Forth, only few patients survived with an unfavourable neurological outcome. This may reflect local practices, as decision of withdrawal of life sustaining therapies is very often shared with patients' family in case of persistent and severe neurological impairment. Certainly, this approach prevented any additional analysis comparing survivors with good to these with poor neurological outcome. Fifth, only patients who received TTM were included in this cohort, although moderate hypothermia is not likely to influence the results. Finally, we could not record the exact time between blood sampling and laboratory analyses. In one study, Vagdatli et al. observed a remarkable decrease in PDW over time together with the absence of platelet activation, even in healthy subjects [24]; as such, samples taken outside working hours or not rapidly addressed to the laboratory for analyses may have underestimated the real PDW value and potentially biased our findings.

\section{Conclusions}

Platelet count decreased during the first $48 \mathrm{~h}$ after CA, while PDW and MPV did not change. Platelets reduction, PDW and MPV were not associated with patient outcome.

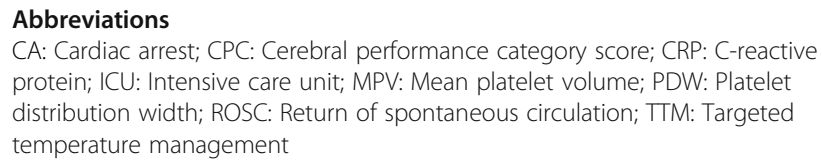
protein; ICU: Intensive care unit; MPV: Mean platelet volume; PDW: Platelet distribution width; ROSC: Return of spontaneous circulation; TTM: Targeted temperature management

\section{Availability of data and materials}

The datasets used and analysed during the current study are available from the corresponding author on reasonable request.

\section{Authors' contributions}

AC: data collection, writing the manuscript and statistical analysis, FF: data collection and statistical analysis, CDeF: development of the study, data collection, JLV: interpretation of the data, writing the manuscript, JC: interpretation of the data, writing the manuscript, FST: interpretation of the data, writing the manuscript. AC, FF, CD, JLV, JC, FST approved the final manuscript.

\section{Ethics approval and consent to participate}

The local Ethical Committee (Comité d'Ethique Hospitalo-Facultaire Erasme-ULB) approved the study (Protocol P2017/264), but the need for informed consent was waived because of the retrospective analysis of data.

Consent for publication

Not applicable.

\section{Competing interests}

The authors declare that they have no competing interests.

\section{Publisher's Note}

Springer Nature remains neutral with regard to jurisdictional claims in published maps and institutional affiliations.

\section{Author details}

'Department of Intensive Care, Erasme Hospital, Université libre de Bruxelles, Brussels, Belgium. ${ }^{2}$ Department of Anaesthesiology and Intensive Care, University of Foggia, Foggia, Italy.

Received: 4 June 2018 Accepted: 18 September 2018

Published online: 25 September 2018

\section{References}

1. Adrie C, Monchi M, Laurent I, Um S, Yan SB, Thuong M, et al. Coagulopathy after successful cardiopulmonary resuscitation following cardiac arrest: implication of the protein C anticoagulant pathway. J Am Coll Cardiol. 2005;46:21-8.

2. Roberts BW, Kilgannon JH, Chansky ME, Mittal N, Wooden J, Parrillo JE, et al. Multiple organ dysfunction after return of spontaneous circulation in Postcardiac arrest syndrome. Crit. Care Med. 2013;41:1492-501.

3. Bro-Jeppesen J, Kjaergaard J, Wanscher M, Nielsen N, Friberg H, Bjerre M, et al. The inflammatory response after out-of-hospital cardiac arrest is not modified by targeted temperature management at $33^{\circ} \mathrm{C}$ or $36^{\circ} \mathrm{C}$. Resuscitation. 2014;85:1480-7.

4. Weidman JL, Shook DC, Hilberath JN. Cardiac resuscitation and coagulation. Anesthesiology. 2014;120:1009-14.

5. Spiel AO, Frossard M, Mayr FB, Kliegel A, Janata A, Uray T, et al. Pronounced platelet hyperfunction in patients with cardiac arrest achieving restoration of spontaneous circulation. Crit. Care Med. 2009:37:975-9.

6. Kim CH, Kim SJ, Lee MJ, Kwon YE, Kim YL, Park KS, Ryu HJ, Park JT, Han SH, Yoo TH, Kang SW, Oh HJ. An increase in mean platelet volume from baseline is associated with mortality in patients with severe sepsis or septic shock. PLoS One. 2015;10(3):e0119437.

7. Ates S, Oksuz H, Dogu B, Bozkus F, Ucmak H, Yanit F. Can mean platelet volume and mean platelet volume/platelet count ratio be used as a diagnostic marker for sepsis and systemic inflammatory response syndrome? Saudi Med J. 2015;36:1186-90. 
8. Gurbel PA, Gattis WA, Fuzaylov SF, Gaulden L, Hasselblad V, Serebruany VL, et al. Evaluation of platelets in heart failure: is platelet activity related to etiology, functional class, or clinical outcomes. Am Heart J. 2002;143:1068-75.

9. Gildo J, Monteiro DM, Oliveira D De, Torres C, Cleide M, Clementino F, et al. Atherosclerosis: Open Access Evaluation of Platelet Parameters as Prognostic Analysis in Cardiac Intensive Care Unit Patients. Atherosclerosis. 2017;2:1-6.

10. Ranjith MP, Divya R, Mehta VK, Krishnan MG, KamalRaj R, Kavishwar A. Significance of platelet volume indices and platelet count in ischaemic heart disease. J Clin Pathol. 2009;62:830-3.

11. Steblovnik K, Blinc A, Bozic-Mijovski M, Kranjec I, Melkic E, Noc M. Platelet reactivity in comatose survivors of cardiac arrest undergoing percutaneous coronary intervention and hypothermia. Eurolntervention. 2015;10:1418-24.

12. Tujjar O, Mineo G, Dell'Anna A, Poyatos-Robles B, Donadello K, Scolletta S, et al. Acute kidney injury after cardiac arrest. Crit. Care. 2015;19:169.

13. Anonymous. Randomized clinical study of thiopental loading in comatose survivors of cardiac arrest. Brain resuscitation clinical trial I study group. N Engl J Med. 1986;314:397-403.

14. Nolan JP, Neumar RW, Adrie C, Aibiki M, Berg RA, Böttiger BW, et al. Postcardiac arrest syndrome: epidemiology, pathophysiology, treatment, and prognostication. Resuscitation. 2008;79:350-79.

15. Högberg C, Erlinge D, Braun OÖ. Mild hypothermia does not attenuate platelet aggregation and may even increase ADP-stimulated platelet aggregation after clopidogrel treatment. Thromb J. 2009;7:2.

16. Nobile L, Taccone FS, Szakmany T, Sakr Y, Jakob SM, Pellis T, et al. The impact of extracerebral organ failure on outcome of patients after cardiac arrest: an observational study from the ICON database. Crit Care. 2016;20(1):368.

17. Wiwanitkit V. Plateletcrit, mean platelet volume, platelet distribution width its expected values and correlation with parallel red blood cell parameters. Clin Appl Thromb. 2004;10:175-8

18. Guclu E, Durmaz Y, Karabay O. Effect of severe sepsis on platelet count and their indices. Afr Health Sci. 2013;13:333-8.

19. Gao Y, Li Y, Yu X, Guo S, Ji X, Sun T, et al. The impact of various platelet indices as prognostic markers of septic shock. PLoS One. 2014:9.

20. Chung SP, Yune HY, Park YS, You JS, Hong JH, Kong T, et al. Usefulness of mean platelet volume as a marker for clinical outcomes after out-of-hospital cardiac arrest: a retrospective cohort study. J Thromb Haemost. 2016;14(10): 2036-44.

21. Jeppesen AN, Kirkegaard H, IIkjær S, Hvas AM. Influence of temperature on thromboelastometry and platelet aggregation in cardiac arrest patients undergoing targeted temperature management. Crit Care. 2016;20:118.

22. Mirabella L, Cotoia A, Colacicco G, Tullo L, Salatto P, Mollica G, et al. Reference values for coagulation assessment in full-term newborns. Minerva Anestesiol. 2017:83:369-74

23. Tilemann L, Mohr SK, Preusch M, Chorianopoulos E, Giannitsis E, Katus HA, Müller OJ. Platelet function monitoring for stent thrombosis in critically III patients with an acute coronary syndrome. J Interv Cardiol. 2018;31(3):277-83.

24. Vagdatli E, Gounari E, Lazaridou E, Katsibourlia E, Tsikopoulou F, Labrianou I. Platelet distribution width: a simple, practical and specific marker of activation of coagulation. Hippokratia. 2010;14(1):28-32.

Ready to submit your research? Choose BMC and benefit from:

- fast, convenient online submission

- thorough peer review by experienced researchers in your field

- rapid publication on acceptance

- support for research data, including large and complex data types

- gold Open Access which fosters wider collaboration and increased citations

- maximum visibility for your research: over $100 \mathrm{M}$ website views per year

At $\mathrm{BMC}$, research is always in progress.

Learn more biomedcentral.com/submissions 